\title{
Representation of the Characters in the Claimed English as an
}

\section{International Language-Targeted Coursebooks}

\author{
Mehdi Solhi Andarab ${ }^{1 *}$ \\ ${ }^{1}$ Istanbul Medipol University, Istanbul, Turkey \\ * Mehdi Solhi Andarab, E-mail: solhi.mehdi@gmail.com
}

\begin{abstract}
The cultural and linguistic hegemony of the native speakers of English over the non-native speakers in the process of language learning and teaching has paved the way for the stereotypical and biased representations of the non-native speakers of English in majority of the English Language Teaching (ELT) coursebooks. Actually, this essentialist approach in the process of materials development is likely to result in reductionist overgeneralization and otherization of foreign societies (Holliday, 1994). However, in recent years, with the advent of English as a International Language (EIL), the issue of native speakerism, the ownership of English, and consequently the cultural content of ELT coursebooks have been the subject of debates. Despite the dominance of native speaker varieties of English in ELT coursebooks, there has been a growing awareness among publishers over the past years and accordingly some EIL-based coursebooks targeted specifically at EIL learners have been published. In this study, a sample group of such coursebooks was subject to close scrutiny. In so doing, an attempt was made to examine the representation of the characters in the claimed EIL-targeted coursebooks. According to the results of the study, despite the claim to be based on EIL, the biased representation of the non-native speakers of English is observed throughout the entire series of the analyzed coursebooks and they superficially surface a stereotypical association of culture and location/country.
\end{abstract}

\section{Keywords}

English as an international language, English as an international language-targeted coursebooks, essentialist and non-essentialist views of culture

\section{Literature Review}

\subsection{Introduction}

As far as language education is concerned, it is generally assumed that materials have a significant role in structuring the English language lesson and continue to play a central role in foreign language education, especially at beginner and intermediate levels (Gray, 2006). That is why many scholars argue in favor of integrating the coursebooks in teaching and learning English. The coursebooks often incorporate culture as part of their content and are considered as the best medium to present the cultural contents to the learners. Crewe (2011) also points to the role of the learning materials in the process of 
learning and teaching, stating that the teaching-learning experience is mainly comprised of three essential entities: the students, the teacher, and the instructional materials. The coursebooks offer structured content in a uniform format for ready implementation. As such, it is a primary resource for use in the teaching-learning process. Haycroft (1998) also underlines the importance attached to the coursebooks in language learning, asserting that they conveniently and compactly serves a number of useful purposes: primarily in giving a notional authority to the teacher as the mediator of its content, but also providing students with a quantifiable record to be studied or learned; the coursebook acts then, as both resource and point of reference. The prominent role that coursebooks play should therefore make them the focus of attention with regard to theoretical and practical ideas on the nature of effective pedagogy (Crewe, 2011).

Many scholars (e.g., Cortazzi \& Jin, 1999; McKay, 2003; Sercu, 2005) underline the significance of culture in the coursebooks. McKay (2003), for instance, argues that students can be assisted to understand a foreign culture through different means. According to her, the coursebooks are paramount in the sense that they are the most commonly used teaching tools in the process of language learning. Cultural contents of the coursebooks, as McKay (2003) highlights, determine the type and extent of the cultural knowledge students are likely to gain in the classroom and therefore they should be regarded as distinctive element of the coursebooks as they are expected to trigger the intercultural competence of the learners. In a similar vein, Cortazzi and Jin (1999) view cultural learning as a dialogue between teachers, students, and coursebooks. In order to both teach a foreign language and to promote learners' familiarity with a foreign culture, teachers rely heavily on coursebooks, though many also use supplementary materials to a larger or lesser extent (Sercu, 2005).

With regard to the cultural content of the materials, in preparing materials for the teaching of a global language, the coursebook writers, as Gray (2002) points out, have to follow sets of guidelines that fall into two areas: inclusivity and inappropriacy. Inclusivity refers to "the need for a non-sexist approach to the way in which men and women are represented throughout the coursebook" (p. 157). Women should not be represented as underrepresented, trivialized and stereotyped in the content of coursebooks. The negative representation of women is likely to adversely affect women students and to cause them to learn less effectively. Inappropriacy refers to "those topics which writers are advised to avoid so as not to offend the perceived sensibilities of potential buyers and readers” (p. 157). According to Gray (2002), guidelines put forward for inappropriacy are different from guidelines for inclusive language and the representation of women and men. The former aims for customers' perceived sensitivities while the latter has the stated aim of improving the learning opportunities for women students and reflecting language change. Put simply, foreign buyers may refuse to purchase materials which are culturally offensive. He introduces lists of taboo topics, which coursebook writers are usually advised to avoid in their attempt to write the materials. These topics include anything that might seem unpleasant to the communities and lead to cancelled contracts or low sales: these avoided topics are introduced under the acronym PARSNIP (politics, alcohol, religion, sex, narcotics, isms, and pork) as a Published by SCHOLINK INC. 
rule of thumb.

\subsection{Hegemony of the Native Speaker Countries in the Language Coursebook}

However, despite the popularity of coursebook in the process of language learning, it is worth noting that the majority of the general English coursebooks are published by major Anglo-American publishers in the native speaker countries. As a result, the hegemony of the native speaker countries is felt in all sections of the coursebooks. In addition, general English coursebooks are criticized for portraying the idealized pictures of English-speaking countries because the cultural content of such materials tends to lean predominantly towards American and British cultures. They also tend to privilege the United States and UK, in terms of both linguistic and cultural contents. What makes it worse is the fact that coursebooks prepared and used in English-speaking countries are also used in countries where English is taught as a foreign language.

Byram (1990) also emphasizes that one of the most criticized issues of foreign language material is their superficial and biased representation of reality. In similar vein, Ndura (2004) points to the stereotypical presentation of the characters and consequent lack of dynamic representation of the native speakers of the target culture. In general, Britishness and Americanness seem to be the standards, and cross-cultural perspectives in communication are deemphasized or denied. Misrepresenting cultures by reinforcing popular stereotypes and constructing these cultures as monolithic, static "others", rather than as dynamic entities is likely to result in failure in making cultural content an effective element in language learning and teaching (Guest, 2002). Reimann (2009) similarly declares that deciding whose culture to represent, and how to present cultural content in the process of language teaching without stereotypes or essentialist perspectives, while keeping information relevant and interesting, has often been problematic. This dilemma stems from the fact that majority of the coursebooks are produced for wide audiences and therefore tend to generalize in terms of skills, acceptable subjects, or cultural content.

\subsection{Emerging Need for EIL-Based Materials in Global Coursebooks}

The role of English in communication has experienced fundamental changes in recent years. These changes have come into existence as a result of globalization and the need for a single language to globally portray and present wide ranges of cultures in the world. This heavy burden on the shoulders of English has made it a language of international communication or in a specialized term English as an International Language (EIL). Mesthrie and Bhatt (2008) define EIL as a general term or in a more specific sense for the use of English between speakers from different countries who do not have English as a mother tongue. Sharifian (2009) specifically points to the difference between "international language" and "EIL". He believes that the use of an adjective plus "English" often suggests a particular variety, such as American English, Singaporean English or Chinese English. Thus, "International English" can suggest a particular variety of English, which is not at all what EIL intends to capture. Therefore, EIL rejects the idea of any particular variety. He defines "EIL contexts" as contexts in which English is used between speakers coming from different cultural and national 
backgrounds. Seidlhofer (2003) claims that in the EIL era "English language no longer belongs numerically to speakers of English as a mother tongue, or first language. The ownership of any language in use belongs to the people who use it, however they are, however multilingual they are, however monolingual they are” (p. 7).

To put in a nutshell, in alignment with the spread of English, a mounting interest in communication and the idea of intercultural learning, there appeared challenges in English language pedagogy, marking a shift (among others) away from the conceptualization of the English language as a tool for understanding and teaching Anglo-American cultural norms. The essentialist approach, which regarded culture in its most typical form as geographically (and quite often, nationally) distinct entity which existed in a fixed and homogeneous (Atkinson, 1999) state, was in time, challenged by a non-essentialist outlook that conceptualized culture as a complex social force that can flow, change, intermingle, and cut across and through one another, regardless of national frontiers (Holliday, Hyde, \& Kullman, 2014). The essentialist view of culture sees culture as a concrete social phenomenon which represents the essential character of a particular nation. In contrast, the advocates of the nonessentialist view of culture see it as a movable concept used by different people at different times to suit purposes of identity, politics and science (Holliday, 2000). Reimann (2009) similarly declares that deciding whose culture to represent, and how to present cultural content without stereotypes or essentialist perspectives, while keeping information relevant and interesting, has often been problematic in the process of language teaching.

In majority of the coursebook developed in the native speaker countries, the essentialist notion of "national culture" has provided a sense of national security for the materials developers and has paved the way for them to express statement like "In the Japanese context students are X". In fact, according to the essentialist view of culture, a Japanese person's behavior is solely and reductively explained in terms of her "Japanese culture”, because the essentialist view considers national culture as a concrete structure within which the behavior of a particular group is placed. Therefore, the behavior of a Japanese person is seen as totally confined by the constraints of a national culture. Therefore, the stereotypical behavior of the Japanese student can only be explained as a departure from Japanese national culture. In contrast, the non-essentialist view of culture caters the resource of a general understanding of how culture intrinsically works, which contributes a framework for analysis of behavior, but it does not impose pre-definitions of the essential characteristics of specific national cultures. It thus avoids cultures entirely by not including reductive statements such as "Japanese students behave like this because this is how the Japanese are". 


\section{Procedure}

The coursebooks have been objects of study for decades. However, it is only during past few decades that they have been studied systematically (Elomaa, 2009; as quoted in Lappalainen, 2011). It was not until the 1990s when researchers started to pay more detailed attention on teaching materials. At present, the importance of teaching materials has been acknowledged and as a result of the fact that English is an international and global language, the critical study of the coursebooks carries a considerable importance. In fact, a great number of studies have been made to generally investigate the issue of cultural content of the ELT coursebooks. However, despite the increasing attention given to the cultural content of the coursebooks, with regard to the recent role of EIL and an inevitable impression of EIL on the forthcoming materials development, particularly global coursebooks, there lie some gaps in need of exploration.

This study investigates a series of EIL-based coursebooks that are committed to the teaching of English in the contemporary world, inquiring whether these coursebooks appropriately represent the both native and non-native speakers of English. The sample consists of three reportedly EIL-based coursebooks that are currently being used worldwide. Selection of these coursebooks was based on their central claims to be based on EIL; international appeal, culturally appropriacy, understanding English across cultures by developing learners' intercultural literacy through awareness of language, awareness of the needs of learners to speak to other non-native speakers as well as to native speakers, the perception of different varieties and speakers, acuity of norms and forms in English and sensitivity towards different cultural and national backgrounds. To illustrate, on the cover page of Global Coursebook Series, the motto of the coursebook appears: in parallel with EIL. In contrast to Global Coursebook Series, which is quite well-known and commonly used in most of the language institutes in many countries, the other coursebooks are extensively used particularly in Asian countries, specifically Japan.

National Standards in Foreign Language Education Project (1996; as cited in Yuen, 2011) conceptualizes the different aspects of culture is terms of "products" (big C), "practices" (little c), and "perspectives" (subjective culture). Moran (2001, p. 25) adds "persons" as the fourth aspect of culture to be considered. Culture with big $\mathrm{C}$ encompasses history, literary works, the formal institutions, fine arts, and the sciences. Small c culture refers to housing, clothing, food, tools, transportation, and all patterns of behavior members of a culture share (Brody, 2003). Perspective entails the values and beliefs, inspirations, world views, and mythology (such as superstitions and horoscopes) that individuals share in a community of speech. Finally, famous individuals and even fictitious or unknown people are the fourth factor of culture that should be taken into close account. In this study, the emphasis was given to the characters, fourth aspect of the culture, in an attempt to investigate whether native or non-native speakers of English are equally presented and whether their representations are based on essentialist or non-essential views of culture. In so doing, the characters in the claimed EIL-based coursebooks were taken into close scrutiny. It is worth mentioning that due to the extensive references to the characters in these coursebooks only some examples are included and analyzed in this 
study.

\section{Findings}

The first coursebook analyzed in the study was English across Cultures coursebook. Although this coursebook purports to be based on EIL, in an extensive number of cases, essentialist notions of culture can be seen within its contents. For example, the authors of the coursebook stereotypically tend to overgeneralize some cultures, using phrases like "In Australia people often say...” (p. 12), "Many Asian cultures...” (p. 13), “Chinese speakers often like to...” (p. 17), "when the British and American talk about cars...” (p. 24), “Chinese way of requesting” (p. 25), “Generally speaking, people in Australia will accept compliments" (p. 29), “This is considered very rude in Japan and Korea” (p. 40), "Westerners and Easterners use eye contact in different ways" (p. 40) and many other examples that can be encountered in English across Cultures coursebook.

It is evident that in many cases the coursebook tends to treat culture as prescribed national and regional entities. It goes without saying that this view of culture in the coursebooks results in reductionist overgeneralization and otherization of foreign societies (Holliday, 1994) and, as aforementioned, the culturist reduction and otherization of "foreign" people is not in parallel with the specification of EIL. Despite all stereotypical references to the national and regional cultures in English across Cultures coursebook, in chapter eleven entitled "National stereotypes" the authors of the coursebook give some examples of national stereotypes of Japanese and Australian people and put some clarification for this stereotypical approach. To exemplify, according to the text on page 48, the Japanese are thought of as serious, reserved people who are polite and do not reflect their emotions. To give another example, in contrast, Australians are thought of as being easy-going or relaxed. Nevertheless, the authors of the coursebook believe that "[A]s with all stereotypes, the Japanese and Australian stereotypes many contain elements of truth, but the images are over-simplified. Stereotypes are also resistant to change and reflect past more than present situations in society” (p. 49). As the quote indicates, the authors of the coursebook actually highlight that some parts of stereotypes can be real but we cannot oversimplify a community of culture by merely treating it as black and white nor we can draw a boundary to restrict culture as an element of a certain nation.

Similar to English across Cultures coursebook, in Intercultural English coursebook, the trace of essentialist approach to culture can be felt throughout the coursebook. To illustrate, on page 2, according to the text, in many Asian cultures it is common to greet someone by asking something like "Have you eaten?" It is noteworthy that the use of the phrase of "many Asian cultures" can pave the way for the emergence of essentialist view to culture. In fact, according to world population statistics, Asia is the world's largest and most populous continent with a population of 4.3 billion people. So the use of "many Asian cultures" can imply more than one billion Asian people and this oversimplification and overgenealization of a cultural theme reflect the essentialist view of culture. The other references of the essentialist approach to culture in Intercultural English coursebook include the examples like "in 
Japan, it is polite to bow” (p. 3), "The Japanese language reflects Japanese culture” (p. 19), "In Australia, the common way a 15-year-old son will address his father is by using a colloquial form of his title, Dad" (p. 26), in Australia, "the students may address their lecturers by their first name" (p. 26), "many Asian learners” (p. 26), “western norms” (p. 27), “Japanese culture” (p. 33), “Japanese people” (p. 38), "in most Australian classrooms" (p. 44), "In Anglo-American societies, it is considered polite to look people in the eye when talking to them, or listening to them” (p. 50). All these examples indicate that despite its claim to be in parallel with the features of EIL, Intercultural English coursebook seems to give priority to the national and regional entities while treating culture. Therefore, this tendency of the coursebook does not hit the mark of the specification of EIL.

As far as the representation of the non-native and native speakers of English is concerned, despite its claim to be based on EIL, biased representation of the non-native speakers of English can also be seen throughout the entire series of Global English coursebook. For instance, in Global English elementary coursebook on page 34, young women in United Arab Emirates are portrayed as people who just meet up at home and when they get together, they have something to eat and talk about everything! The photo depicted on the same page also represents a typical gathering of young women in UAE with a scarf covering their hair symbolizing a religion. The stereotypical representation of a typical group of Arabic young women is biased and unrealistic overgeneralization of an Arabic community. We cannot generalize a community stating that all young women in a particular society just meet at home rather than socializing outdoors. On the contrary, biased and unrealistic depiction of native speakers of English is seen on the same page; three old-aged American people are portrayed in a picture indicating that these people normally go to the mall, sometimes see a film and go shopping. Neither this representation of native speakers of English in the US spending time and socializing outdoors, nor the young women who prefer to spend time at home are realistic and both constitute overgeneralized depictions of cultural communities that tend to privilege one group (native speakers of English) over the "other" (its non-native speakers).

Another example of stereotyping and one-dimensional national representation of both native and non-native speakers of English in Global English elementary coursebook can be seen on page 49. There are two pictures on this page, one of which portrays a typical American family and the other one represents a Guatemalan family. The American family is stereotypically presented as a pizza and fast food lover. In contrast, the Guatemalan family is depicted as one who prefers organic food and vegetables. On page 59, there is another picture illustrating a group of poor African children watching an old TV while sitting on the ground somewhere outdoors. This stereotypical and unrealistic representation of an African country implies the life in Africa and tends to overgeneralize an African community. Another stereotypical depiction of different ethnic groups in Global English elementary coursebook is presented on page 97. On this page, there are four characters giving some information about themselves. Three of them come from different colors and ethnic groups; the first one is an economic migrant who has left her country to have a better life for her children. The second one is a Published by SCHOLINK INC. 
refugee who has left his country because it was dangerous to life there. The third one is a Chinese postgraduate student who has left his country to have a better educational opportunity abroad. As it is implicit, the depiction of a country with different colors and ethnic groups other than white is not realistic. The fourth picture illustrates a white retired family who want to live somewhere nice with nice weather. This idealistic representation of people is a biased depiction of ethnicity that privileges one group at the expense of others.

\section{Conclusion}

Hartmann and Judd (1978) indicate how many American EFL materials present stereotyped portrayals of men and women (often to the detriment of the latter), through one-sided role allocation, overt stigmatization, or simple omissions. Likewise, Clarke and Clarke (1990) point to numerous instances of stereotyping in British EFL materials in areas of gender, race, class, and religion. They maintain that EFL materials insist on stereotypes when they omit, consciously or unconsciously, important defining aspects of a society. The numerous instances of stereotyping in EFL materials and stereotypical representation of native speaker culture in instructional material aggravates the problem of presentation of the target language in relation to its own culture (Clarke \& Clarke, 1990). The ELT coursebooks construct particular images of native speakers, mostly with highly positive characteristics, so it would not be surprising to see nonnative speakers attempting to assimilate those identities by imitating native speaker accents in their English (Sharifian, 2009). As it is evident in this study, the contents of the analyzed coursebooks addressing the presentation of the characters rarely addresses social issues; instead they portray stereotypical families and cultures that are apparently homogeneous. Resonating the essentialist approach to the presentation of characters in a majority of the ELT coursebooks, according to the results of the study, the coursebooks series analyzed in this study similarly surfaced a stereotypical association of culture and location/country.

In brief, either due to stereotyped or restricted perspective of the foreign communities, the current foreign language coursebooks have not succeeded in reflecting social reality (Byram, 1990). Instead of portraying native speakers of English as ideal community who live in a utopian society, the equal emphasis should be paid on more unbiased representation of native-speakers of English. In sum, the future coursebooks should strike a balance between the fair representation of both native and non-native speakers of English. All these scholars suggest that applied linguists and publishers will need to find ways of promoting a EIL perspective in teaching materials, including coursebooks. They invite publishers to develop EIL-oriented materials. Due to the fact that the native speaker norms and cultures are represented as the most ideal patters to follow in the coursebooks, the learners see the native speaker varieties and cultures as superior to their own cultural values and beliefs. Instead of merely empowering the native speaker norms and cultures in the coursebooks, equal attention should be allocated to the non-native speaker varieties of English and trigger equal balance in presentation of the characters in the coursebooks. The coursebooks could include texts written and spoken in different 
varieties of English, as well as those produced by native speakers, and examinations could start rewarding effective communication and stop penalizing non-standard pronunciation and grammar which in no way impedes communication.

With the advent of EIL on the one hand and the importance of ELT coursebooks on the other hand, there seems to be a growing need to develop coursebooks to equip language learners with an EIL awareness because these learners are most likely to communicate with English users from other countries. However, with only limited potential to promote the acquisition of intercultural competence in learners, either because of cultural contents of the coursebooks or deficient approach used in the coursebooks to include intercultural competence, the current language coursebooks seem to be unable to fulfill the requirements of EIL. Therefore, in terms of language learning materials in general and coursebooks in particular, the rise of EIL suggests that the traditional use of the native speaker cultural content in ELT texts needs to be reexamined. A number of suggestions can be offered for the composition of future coursebooks regarding the treatment of cultural content. These can be listed as following:

\subsection{Target Community Culture Rather than Merely Native-Speaker Culture}

Both ELT coursebooks and the ELT curriculum should provide an opportunity for learners to foster their cultural awareness by including global and multicultural perspectives (Shin, Eslami, \& Chen, 2012). Using the source culture should be considered as a means of empowering the students and encouraging them practice using English to express their own culture and identity. McKay (2002) similarly argues that materials from the source culture (i.e., the learners' culture) and international culture must also be included in the coursebooks. In a globalizing perspective, equal value should be placed on both non-native and native speakers' cultural knowledge regarding the both target and local elements in teaching materials.

\subsection{Literatures in English Rather than Solely English Literature}

Despite the existence of a wealth of literature in non-native speaker countries, little or none of this is referred to in the coursebooks. In the majority of coursebooks, the nearly all attention is devoted to the British and American literature and language learners are being exposed to a canon of literature that encompasses works of English or American novelists, writers, and poets. Global English, for instance, is one of the coursebooks with heavy emphasis on literary works of the native speaker countries. Throughout the entire series of the coursebooks, a bombardment of literary works of native-speakers of English is presented, with very few literary works from various non-native authors (whose literary works have been written in English) are present. The heavy use of literary works of native-speakers of English in the coursebooks is in not in parallel with the main objectives of EIL-based coursebooks. 


\subsection{Unbiased Representation of both Native and Non-Native Speakers of English}

As aforementioned, the unbiased and accurate representations of the characters in the coursebooks carry significance in the process of preparations of the materials. The utopian and biased representation of the native speakers of English and the heavy and sole emphasis on them in the coursebooks are not in parallel with the specifications of the EIL. Hence, the due attention needs to be given to both native and non-native speakers of English in the coursebooks.

\subsection{Cultural Liberty Rather than Cultural Literacy}

According to Shin, Eslami and Chen (2012), future textbooks should focus not only on cultural facts but also on deeper beliefs and values. Kumaravadivelu (2011) similarly argues in favor of "cultural library" rather than "cultural literacy". According to him, in our globalized world, as far as learning cultures is concerned, more attention needs to be given to learning "from other cultures", rather than “about other cultures”. Learning about other cultures leads to cultural literacy. In contrast, learning from other cultures leads to cultural liberty. According to him, rather than promoting superficial cultural artifacts like "food", "fashion" or "festivals" as cultural literacy in the classroom, we need to go much deeper into the contemporary realities which shape and reshape cultural identities in our world. He adds that one possible alternative is to create critical cultural consciousness among learners. Developing global cultural consciousness promotes not just cultural literacy but also cultural liberty, paving the way for individual's genuine cultural growth (Kumaravadivelu, 2008).

4.5 Emphasis on Dialogues Taking Place among Non-Native Speakers of English Rather than Dialogues among Native Speakers or among Native and Non-Native Speakers of English

The future coursebooks are expected to include main characters with different varieties of English and assign them bigger roles in chapter dialogues than the minimal roles they currently have. Some dialogues that either represent or refer to the use of English as a lingua franca in different countries could also be added to chapters (Matsuda, 2003). Also, the presence of characters from countries other than the native speaker countries would make the inclusion of cultural topics and pictures from those countries easy.

\section{References}

Atkinson, D. (1999). TESOL and culture. TESOL Quarterly, 33(4), 625-654.

Brody, J. (2003). A linguistic anthropological perspective on language and culture in second language curriculum. In D. Lange, \& R. Paige (Eds.), Culture as the core: Perspectives in culture in second language learning (pp. 37-51). Greenwich, CN: Information Age.

Byram, M. (1990). Foreign language teaching and young people’s perceptions of other Cultures. In B. Harrison (Ed.), Culture and the Language Classroom (pp. 76-87). London: Modern English Publications and the British Council.

Clarke, J., \& Clarke, M. (1990). Stereotyping in TESOL materials. In B. Harrison (Ed.), Culture and the Language Classroom (pp. 31-44). London: Modern English Publications and the British

Published by SCHOLINK INC. 
Council.

Cortazzi, M., \& Jin, L. (1999). Cultural mirrors: Materials and methods in the EFL Classroom. In E. Hinkel (Ed.), Culture in Second Language Teaching (pp. 196-219). Cambridge: Cambridge University Press.

Crewe, J. (2011). How far do “global” ELT coursebooks realize key principles of Communicative Language Teaching (CLT) and enable effective teaching learning? Retrieved on April 2013 from http://www.birmingham.ac.uk/Documents/collegeartslaw/cels/essays/matefltesldissertations/Crew eDissertation.pdf

Gray, J. (2002). The global coursebook in English language teaching. In D. Block, \& D. Cameron (Eds.), Globalization and language teaching (pp. 151-167). London: Routledge.

Gray, J. (2006). A Study of Cultural Content in the British ELT Global Coursebook: A Cultural Studies Approach. Doctorate Dissertation.

Guest, M. (2002). A critical “checkbook” for culture teaching and learning. ELT Journal, 56(2), 154-161.

Hartman, P., \& Judd, E. (1978). Sexism and TESOL materials. TESOL Quarterly, 12(4), 383-392.

Haycroft, J. (1998). An introduction to English language teaching. Longman.

Holliday, A. (1999). Culture as constraint or esource: Essentialist versus non-essentialist views. Iatefl Language and Cultural Studies SIG Newsletter, 18, 38-40.

Holliday, A. R. (1994). Student culture and English language education: An international context. Language, Culture and Curriculum, 7(2), 125-143.

Holliday, A., Hyde, M., \& Kullman, J. (2004). Intercultural Communication: An Advanced Resource Book. London: Routledge.

Kumaravadivelu, B. (2008). Cultural Globalization and Language Education. New Heaven and London.

Kumaravadivelu, B. (2011). Language Teacher Education for a Global Society. Routledge Publication.

Lappalainen, T. (2011). Presentation of the American Culture in EFL Textbooks: An analysis of the cultural content of Finnish EFL textbooks for secondary and upper secondary education (Master's dissertation). Retrieved on April 2013, from https://jyx.jyu.fi/dspace/bitstream/handle/ 123456789/26866/URN\%3ANBN\%3Afi\%3Ajyu-2011050310724.pdf?sequence=1

Matsuda, A. (2003). Incorporating world Englishes in teaching English as an international language. TESOL Quarterly, 37(4), 719-729.

McKay, S. L. (2002). Teaching English as an International Language: Rethinking Goals and Approaches. Oxford: Oxford University Press.

McKay, S. L. (2003). Toward an appropriate EIL pedagogy: Re-examining common ELT assumptions. International Journal of Applied Linguistics, 13(1), 1-22.

Mesthrie, R., \& Bhatt, M. R. (2008). World Englishes: The Study of New Linguistic Varieties. UK: Cambridge University Press.

Published by SCHOLINK INC. 
Moran, P. R. (2001). Teaching culture: Perspectives in practice. Heinle and Heinle, Boston, Mass.

Ndura, E. (2004). ESL and cultural bias: An analysis of elementary through high school textbooks in the western United States of America. Language, Culture and Curriculum, 17(2), 143-153.

Reimann, A. (2009). A Critical Analysis of Cultural Content in EFL Materials. Retrieved on October 2012, from http://www.uuair.lib.utsunomiyau.ac.jp/dspace/bitstream/.../28-8-reimann.pdf

Seidlhofer, B. (2003). A concept of international English and related issues: From "real English" to "realistic English". Strasbourg: Council of Europe. Retrieved from http://www.coe.int/ t/dg4/linguistic/source/ seidlhoferen.pdf

Sercu, L. (2005). The Future of Intercultural Competence in Foreign Language Education: Recommendations for Professional Development, Educational Policy and Research. In Sercu et al. (Eds.), Foreign Language Teachers and Intercultural Competence (pp. 160-185). Multilingual Matters LTD.

Sharifian, F. (2009). English as an International Language: An Overview. In F. Sharifian (Ed.), English as an International Language Perspectives and Pedagogical Issues (pp. 1-18). Multilingual Matters.

Shin, J., Eslamia, Z. R., \& Chen, W. (2012). Presentation of local and international culture in current international English-language teaching textbooks. Language, Culture and Curriculum, 24(3), 253-268.

Yuen, K. M. (2011). The representation of foreign cultures in English textbooks. ELT Journal, 65(4), 458-466. 